\title{
To Predict with Confidence, Plan for Freedom
}

\author{
Jarrett Walker \\ Jarrett Walker + Associates
}

What will urban transportation be like in 10-20 years? How will automated vehicles interact with social and cultural trends to define the city of tomorrow? Will the vehicles of the future be owned or shared? How will pricing evolve to motivate behavior? What will happen to public mass transit? What other innovations can we expect that will transform the landscape?

This paper, which is merely the outline of a larger argument, suggests three interconnected answers.

- We can't possibly know. History has always been unpredictable, punctuated with shocks, but if the pace of change is accelerating, then unpredictability may be increasing too.

- We can reach many strong conclusions without knowing. A surprising number of facts about transportation, including some fairly counterintuitive insights that would be transformative if widely understood, can be described and justified solidly with little or no empirical ground, because they are matters of geometry and physics or of nearly axiomatic principles of biology.

- Prediction may not be what matters anyway. If we abandoned hope of predicting the future, we could still describe a compelling outcome of transportation investment, one that motivates many people who will never care about a ridership prediction or economic impact analysis. We could also predict it in the sense that we can predict the continued value of pi. That idea is freedom, as transportation expands or reduces it.

\section{The Limitations of Prediction}

When I presented a proposal for redesigning Houston's bus network to the board of directors of the transit agency there, the board chair asked me: "What will the ridership growth be?" When it became clear that nobody wanted to hear me explain why ridership is not really predictable, or why other outcomes might matter more, I offered my best professional guess: $20 \%$ ridership growth after two years, net of all external changes. A run of the regional model later came up with the same answer.

(C) 2018 Jarrett Walker

http//dx.doi.org/10.5038/2375-0901.21.1.12

ISSN: 1077-291X | Licenced under Creative Commons License Attribution - Noncommercial 4.0

The Journal of Public Transportation is published by the Center for Urban Transportation Research 
Two years after the plan was implemented, there is no way to prove that prediction wrong or right because many events have impacted Houston and the business of urban transportation. Gas prices have fallen, causing job losses in Houston's petroleum-based economy as well as increasing driving overall. Uber and Lyft have grown their market share. There are also internal factors that are hard to separate: Houston Metro opened two light rail extensions in the months before the bus network plan was implemented. Even if those events had been farther apart, the process of ridership growth after an improvement can take years.

When I said my prediction was "net of all external changes" I was defining the limits of what our network design could be responsible for, as you would expect a careful consultant to do. But in saying that, I was also rendering my claim unverifiable. There is no widely agreed upon way to sort out the causes of ridership, so there is no way to know the actual ridership change "net of external changes." Under duress, I had performed a prediction but not really made one.

To some who hear this, it sounds as if I have confessed to some sort of con. But I had said what I meant, and I had given the board everything that I could responsibly offer. While I could not give them certainty about the future, my willingness to make an educated guess conveyed that I am a responsible professional whose view is worth taking seriously. Making predictions, even untestable ones or ones that nobody will care about later, are part of the cultural process for establishing authority.

Political statistician Nate Silver's fame rests on having predicted the outcome of the 2012 presidential election in every state, and all but one state in 2008. But what Silver really predicted was a distribution of possible vote percentages for each state, each indicating that one candidate had slightly better odds than the other. He was fortunate that every state's outcome landed in that better-than-50\% part of its predicted probability range, because he certainly had no basis for predicting that (Silver 2012). Still, the notion that he predicted-in the sense of seeing the future-is the basis of his mystique.

Prediction is also the essence of the sales pitch "Buy this, and you will be happy." Purveyors of technology have always regaled us with exciting predictions of how life will be in the future. Can we sort out the role of self-interest in the predictions we hear? Do the ultimate consumers of these predictions even want to?

None of this is to question the tremendous value of good predictions, or the work of modeling in fields from climate to transportation. The models worth trusting, though, are not just predictions but descriptions of mechanisms whose operations are more or less understood. Weather forecasting is more reliable than political forecasting for exactly this reason.

There have been great ages of theory in urban planning, but ours is an age when empiricism reigns. Data, preferably big data, suffuses transportation debates as though it were a final authority, as though one could translate data into information without assumptions. But we do not need to do more experiments to verify the value of pi, or the fact that organisms consume nutrients and excrete waste. These concepts are axioms, deriving from our definition of a circle, and of life, respectively. You could argue that pi is true in Euclid's space but not Einstein's, so let's add an important clarification: These principles are undoubtable axioms of the world at human scale, the world we are talking about in urban planning. 
A key feature of this kind of knowledge is that to know it is true now is to know it is true throughout time and space. To know what pi is, and to know what kind of knowledge it is, is to know the value of pi in 2040, and on Mars.

What mechanisms could we describe if we confined ourselves to such concepts, avoiding the more empirical terrain of social and cultural studies? What predictions could we make, with a level of confidence that is not just a spread of probabilities, but real certainty about the future? To think about the future, let's think about something equally unknowable: an alien world.

\section{Bortworld: A Thought Experiment ${ }^{1}$}

Suppose that somewhere else in the universe, there's another planet with intelligent life. We don't know what they look like, or what gases they breathe, or whether they're inches or miles tall. We don't know whether they move by hopping, drifting, or slithering. We don't know what they call themselves, so let's call them borts. Let's make just a few assumptions about them.

First, let's assume that the borts tend to cluster in certain places on their planet, which enables trade, creativity, ritual, or whatever other activities give value to their lives. Let's call these places cities. Since cities are places where borts are relatively close together, they have relatively little space per bort. Cities, by definition, are places where space is scarce.

Second, assume that these cities are large enough that a bort can't easily hop, drift, or slither around the city fast enough to reach all the needs and pleasures of daily life. Given this reality, they must have invented vehicles of some kind that carry them faster and farther; if they hadn't, their cities could not have grown so large. The causation can just as well be described the other way: Because borts have invented such a vehicle, their cities are now too large to be reached solely by hopping, drifting, or slithering.

Do we have to make an assumption about their communications? If the borts had either perfect telepathy or perfect virtual reality, then they would never need to move for any of the purposes of interaction. But in this case, why would they have cities? Let's assume-because this really arises from assumption number two-that their communications are not so perfect, and that they do need to move around to do whatever borts do. Specifically they would not be in cities if they did not need to meet each other in physical space, which requires two or more borts to show up at the same time. So the borts must have a concept of timeliness, which implies the possibility of haste and an interest in travel time.

Scarcity of space, as of any resource, triggers the law of supply and demand. For any organism, securing a scarcer resource requires a greater expenditure of energy. Call this energy expenditure the price. Social structures may affect who pays this price, but it must be paid.

Perhaps the borts have tried using a personal locomotion vehicle in their cities. Call it a bortcar. It gives a bort freedom to move at high speeds, but it's much bigger than the bort's body, so it takes much more space per bort inside the city, all the more because the faster it

\footnotetext{
'This section is adapted from my article "How Universal Is Transit's Geometry?" HumanTransit.org. Blog, March 1, 2011.
} 
moves the more space it needs for stopping distance. To say nothing of parking or storage. Only a world of perfectly balanced demand, where trip origins and attractions were evenly matched at every moment, would no storage be needed, even in a world of automated bortcars. These vehicles will not fit well into the low space per bort that is the city's defining feature. If there are no alternatives and disincentives to bortcar use, the result will be congestion. Whenever a scarce resource is priced below its true cost (as with half-price ticket sellers or Soviet grocery stores) a queue will form, and that is what congestion is. If you don't pay in money, you will pay in time.

To address this problem, bort society would have to have selected some mix of the following solutions:

- Reduce the amount of travel through limiting use. Bort society may have mechanisms for deciding who can drive a bortcar in the city and who can't. These may be expressions of hierarchy, or rationing systems, or some kind of exchange with other objects of scarcity-i.e., pricing.

- Reduce the amount of travel through mixed-use urban planning. A more egalitarian way to the same end is to design the city to minimize the travel borts need to do to do whatever they do. We call this mixed-use planning. Borts must have a similar issue because they go places to meet one another, so it matters where those places are.

- Faster individual movement in very little space. The borts may have invented small vehicles that allow them to move faster without taking up much more space than a bort does itself. Call them bortcycles, though they could just as well be bortjetpacks or bortsegways.

- Increase vehicle occupancy. Sharing bortcars will work at small scales, but at high density where the shortage of space per bort is acute, only larger vehicles, some form of mass transit, will let every bort travel as needed within that constraint.

If the problem is congestion, these are the options. No others are mathematically coherent. There are solutions that soften these problems around the edges, such as allowing automated bortcars to join temporarily into trains, but none that transform the basic math. For example, if bortcars join to form trains, then there are still areas where they run alone; if not, borts would just use a train. If bortcar trains are assembling and separating within the complex pattern of everywhere-to-everywhere travel inside a dense urban core, then there will still be plenty of solo bortcars where space is scarce, which returns us to the same geometry problem. The acts of separation and joining, especially if performed at speed, will also take space. These bortcar trains could use space and energy efficiently where there is longer distance travel and densities are lower, such as between what we would call outer suburbs. But that is not where the worst problem of space lies.

Any combinations of these tools will also have to manage their conflicts, which at higher speeds will require a degree of separation. Bortcycles, which can't be as armored as bortcars, will be dangerous if too vulnerable to collision with bortcars. Borts hopping, drifting, or slithering under their own power will face the same danger. Likewise, bort transit vehicles will be less useful if stuck in the congestion generated by single-occupant bortcars, so their success in this context would require a large portion of bort society to have no alternatives but to use them. 
To get this far, the only assumptions l've made are those needed to generate active cities and a problem of transportation. Other than that, I've been relying on concepts about which we have perfect or near-perfect certainty. Geometry defines the facts of urban space. Physics governs crash risk in relation to speed. The concept of scarcity-and thus the interaction of supply and demand-is biological but will exist for anything that we could recognize as an organism, so we have assumed this in assuming that we can think about the borts at all.

In short, if I confine myself to this kind of knowledge, I can make absolutely confident predictions about our world. After several more decades of exponential technological and cultural change, a future studded with surprises, our world will continue to resemble the bort world in all the respects l've described. Technology never changes facts of geometry or physics, at least not as experienced at human scale. By technology I specifically mean inventions rather than discoveries.

We could go much further, and lay out many of the facts about how vehicle sharing works. Obviously we can't predict bort ridership patterns, but there is a powerful thing we could describe and predict: Borts will have a degree of freedom defined by where they could get to in a fixed amount of time. This degree can be visualized as an isochrone around the bort's location, as in an example from our own world shown in Figure 1.

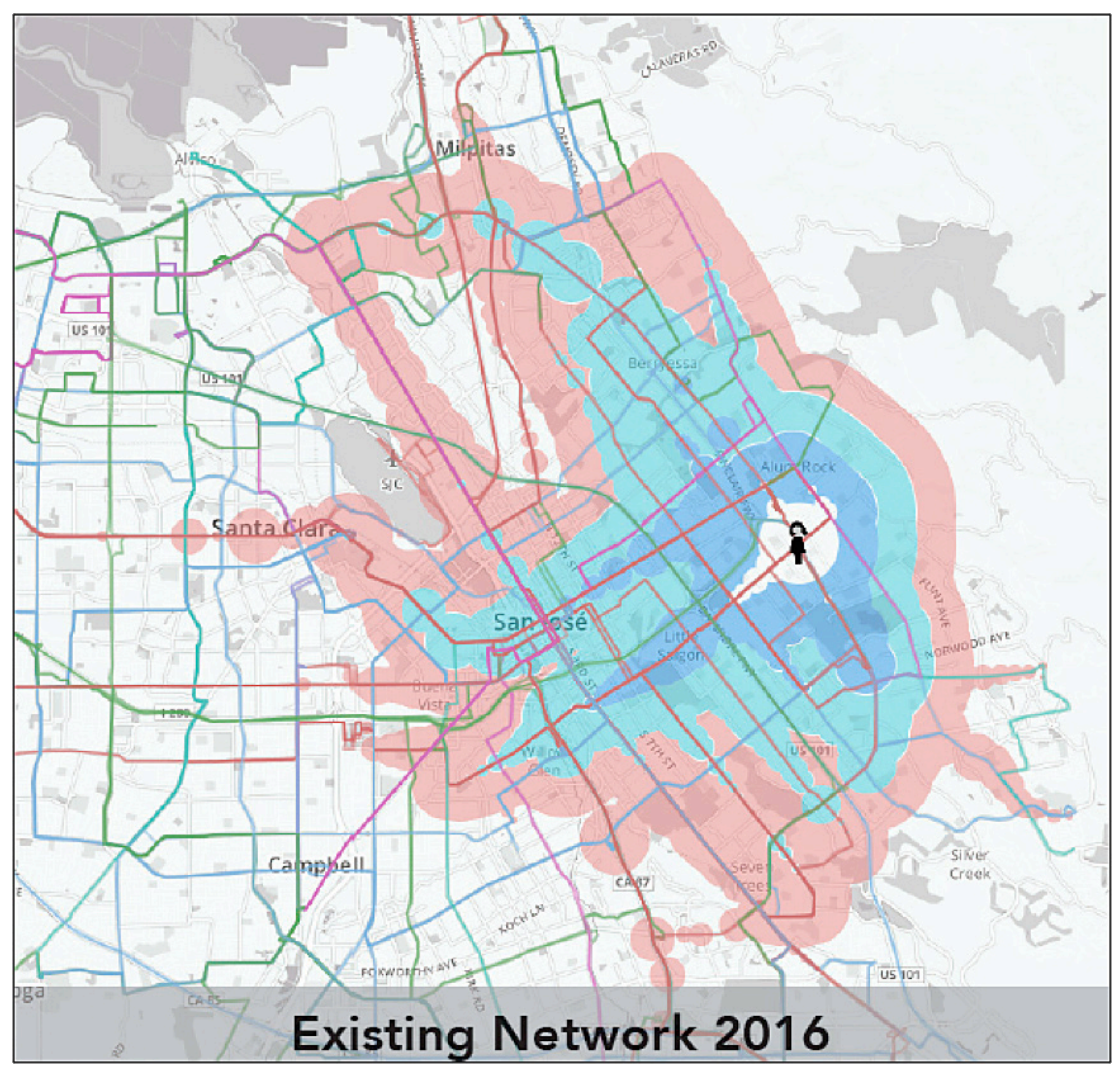

\section{FIGURE 1.}

Isochrone showing where a person at a given location could get to, on transit plus walking, in $15,30,45$, or 60 minutes. (Walker and Associates 2016) 
The size and shape of this isochrone can be geometrically derived from several features about a public transit network. Of course, borts, like us, may be more interested in going to destinations than just covering distances, so what matters is what is in those isochrones, not just their size.

If the goal is to get as many trip attractions as possible into the isochrones of as many trip generations as possible, transit service would be focused on places that are dense. Density-a purely geometric concept-means that more homes and trip attractions are near each possible public transport stop. That means that a larger share of the population has access to its benefits, and that an isochrone of any size will contain more useful destinations. Therefore a network that optimizes isochrones for the most borts will be most useful to bort homes and activities located at higher densities.

Other factors about where borts live will also determine the potential for transit to expand their freedom. The ease with which they can hop, drift, or slither to their transit stops and the degree to which their development pattern is conducive to running transit in straight lines are also predictable from our assumptions. Even the large-scale mixture of uses in the city is a geometric fact with geometric consequences: If all the borts need to go in one direction at the same time, because their homes are on one side of the city and their destinations are on the other, up to half of all bort transit resources will be spent running empty in the opposite direction, producing a network that is less cost-effective at maximizing freedom for the most possible borts.

We can even predict that bort transit travel will be governed by the main ingredients of transit travel time: frequency, in-vehicle travel time, and access time to/from stops. This will give rise to the same network design strategies we use. For example, the high effectiveness of the highfrequency grid at expanding many borts' access is a fact for bortworld, as it is of ours.

But are the fixed routes l've been describing obsolete? Who wants to hop, drift, or slither to a bus stop? Why can't there be little vehicles that go to where each bort is, and then exactly where they want to go? Bort taxis may exist, and maybe they can be scaled up so that they carry a few borts going in the same general direction. But deviating to particular borts takes a lot of time, and that will mean fewer borts can be served in every hour a bort transit vehicle is operating.

Who cares, if the vehicles are cheap to operate? Maybe they're automated. But even if this could be made energy-efficient compared to fixed transit, there will still be that ultimate geometry problem: space. Any demand-responsive vehicle will be useful to fewer borts, while taking more space, than an effective network of large fixed route vehicles. If the bort city grows in any dimension, this problem will grow more acute. Higher density means more borts competing for the same street space. Horizontal growth means longer average trip distances, which also means each bort needs more street space. Where space is scarce, borts are most effectively served if they gather at stops located along a defined path. The higher the space efficiency required, the more fixed the route has to be.

All this must be as true for the borts as for us, because all this arises, geometrically, from our basic assumptions without reference to culture or behavior. Wherever there are cities in which large numbers of people must travel beyond their walking distance, this will be the math.

To be more precise, these assumptions arise without reference to the sort of behavior that can only be studied empirically. There are facts of behavior that are axiomatic to the idea of an organism, such as eating and excreting. If you must predict human behavior, it is safest to predict 
behavior that has been evident far into the past. Marchetti's constant, an estimate of human tolerance of travel time derived from the study of ancient cities, is an example. Evolutionary explanations based on the conditions of prehistoric human life are even firmer. This is practically the opposite of how human behavior is predicted in many contexts today, where the claim is really about the continuation of recent and therefore possibly transient fads. Streetcars in the United States were popular in the 1920s, despised in the 1950s, and popular again in the 2000s. On what ground do we predict that they will be popular in the future?

\section{Can We Predict Anything Useful?}

We could never predict ridership on the bortworld, but we can predict something that they probably care about and that humans certainly do. To plan without prediction is to plan for freedom. Rather than trying to predict what people will do, what if we tried to maximize what they could do?

We hear little about freedom as a planning outcome, but businesses selling transportation talk about freedom incessantly. Airlines want you to know about all the places you could go. New private entries into the taxi market such as Uber and Lyft want you to feel free to go anywhere in your city in a way that government-protected taxi monopolies never bothered to advertise. A century ago, freedom - the sudden expansion of "where you could go"-was the winning argument for the private car, one that overran thousands of prescient objections about how private cars could damage our cities, our health, our environment, and even our manners.

Yet the transportation professions seem reluctant to discuss freedom as an outcome of transportation planning. Most evaluation focuses on things that can be organized under the "triple bottom line." This trinity of types of impact-economic, environmental, and socialencompasses many urgent goals, but these goals all describe outcomes in a predicted society. They require us to study and predict what people do, but they assign little value to what people have the option of doing-which is to say their freedom. Prediction and freedom are opposites: to the extent we can predict your behavior, you are not free.

When you went shopping at a particular store, does it matter that you could have gone shopping somewhere else, or shopped online while in bed, or embraced an ascetic spiritual path of buying as little as possible? A study of freedom would be intensely interested in that, while conventional planning would merely record what you did and use that to predict what you, despite your illusion of freedom, will continue to do.

When freedom goals do appear in planning, they do so half-concealed, usually in relation to some economic or social outcome that will result from people being free. Policy makers worry about access to jobs, education, and other opportunities. The discussion of equity in transportation (though often hung up on concepts like "minority neighborhoods" or "minority routes" that imply demographic determinism) is also, at its best, a study of the equal distribution of freedom.

The most robust freedom claims that appear in transportation planning are about changes in travel time. Reframing this concept is the key to making freedom visible and quantifiable as a possible evaluation criterion. Not just the freedom to do what some public policy wants you to do-find a job, get training - but freedom in the broadest sense. 
It may seem too broad to use freedom to talk about what is technically called access or accessibility. There are freedoms that you could exercise without transportation, mostly online, but many freedoms still require leaving the house (again, short of perfect telepathy and virtual reality). Once you must go places to do things, access and freedom are the same.

A map of your freedom - of where you can go and thus what you can do-is an isochrone, as in Figure 1. The isochrone is not a new concept and what it describes-changes in accesshas always been a key input to predictive models. But it's only recently that we are looking at it, discussing it in public, and finding the courage to speak of the freedom it describes. A leader in this field is the Accessibility Observatory at the University of Minnesota, whose most recent publications (soon to be updated) are called Access Across America. These analyses show where you could get to in a specified amount of time for each point in a city, and are computed for different modes: walk, bike, walk plus transit, and auto.

You can look at an isochrone for a specified location of interest, such as your house, or a possible business site, or a community of concern. You can also draw an access heatmap of a city, as in Figure 2, which colors each pixel based on the number of jobs or residents that you can get to from there, by a specified mode, in a fixed amount of time. This would have obvious relevance to how the real estate and development industry understands transit access.

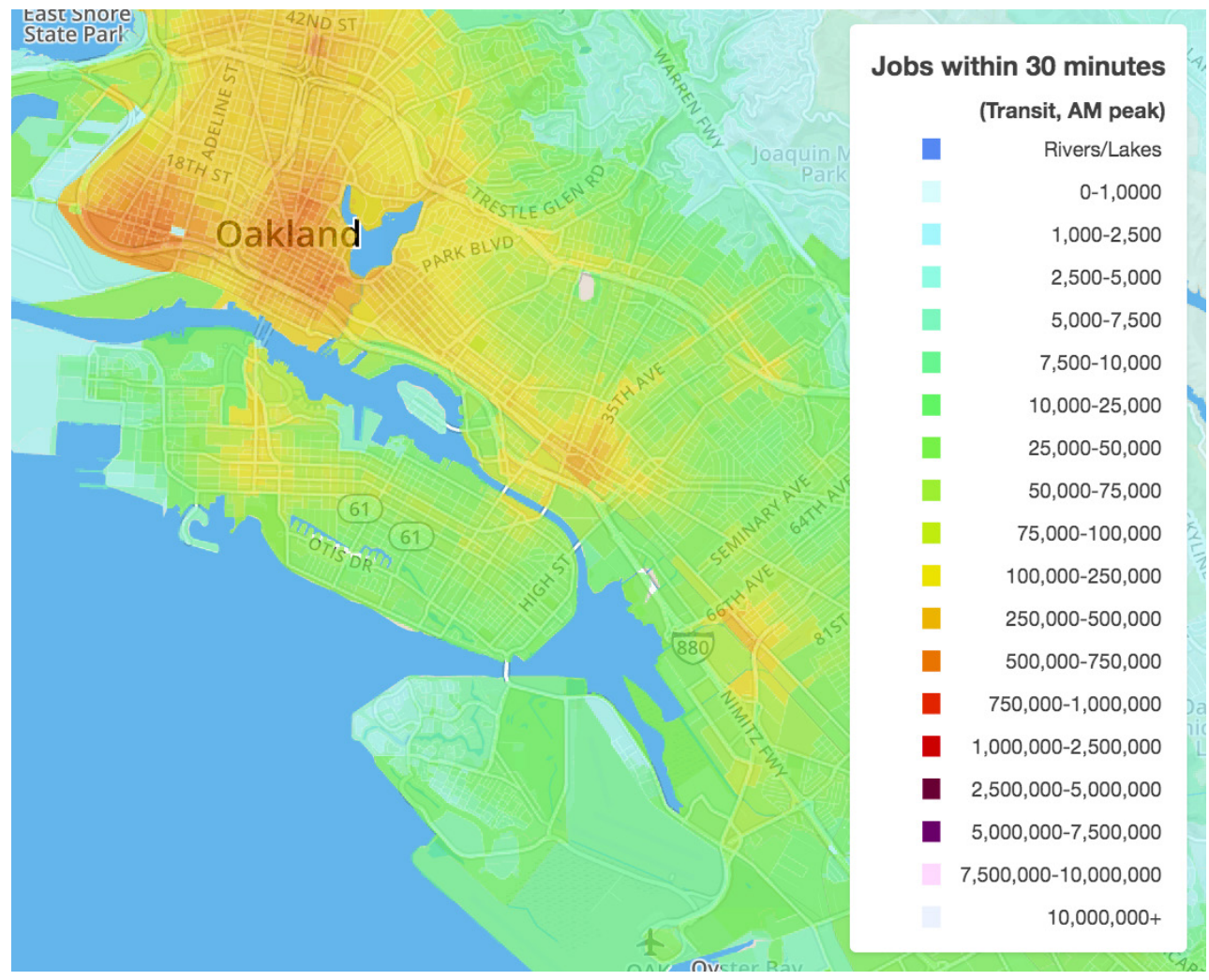

\section{FIGURE 2.}

Heatmap showing how many jobs can be reached on transit from each point in Oakland, California. (Owen et al. 2016) 
To sum up, freedom should be a central evaluation criterion for transportation projects and equity analysis for two reasons:

1. People care about freedom. Showing people their freedom speaks to something they value, even if they don't care about predictions. If journalists could be encouraged to write about freedom instead of predictions, their work would be "news you can use."

2. Freedom is largely predictable because its quantification relies almost entirely on geometry: the design of a transportation network in relation to urban structure. ${ }^{2}$ No sociology or psychology is required, and there is no risk of presuming the permanence of transient fads through the assumptions of a model.

Imagine, for example, if discussions of transit oriented development looked at where you could get to if you lived at a proposed site, rather than just whether an attractive transit technology is running nearby. Imagine if equity were understood as the just distribution of freedom to go wherever you want, as only an isochrone can measure. Imagine if planning documents spoke respectfully of people's freedom rather than only of how experts can predict their behavior. Such things are possible.

\section{References}

Owen, A., B. Murphy, and D. Levinson. 2016. Access Across America: Transit 2015. Final Report No. CTS 16-09. Center for Transportation Studies, University of Minnesota. http://ao.umn. edu/research/america/transit/2015/index.html.

Silver, N. 2012. The Signal and the Noise: Why So Many Predictions Fail-but Some Don't. New York: The Penguin Press.

Walker, J., and Associates. 2016. Transit Alternatives Report. Santa Clara Valley Transportation Authority. http://vtaorgcontent.s3-us-west-1.amazonaws.com/Site_Content/TRIP\%20 Alternatives\%20Report\%20Web.pdf.

\section{About the Author}

JARRetT WALKeR, Ph.D. (jarrett@jarrettwalker.com) is the head of Jarrett Walker + Associates, a transit planning firm based in Portland, Oregon. He has been a consultant in public transit network design and policy since 1991, working across North America but also in Europe, Russia, Australia, and New Zealand. He is the author of Human Transit: How Clearer Thinking about Public Transit Can Improve Our Communities and Our Lives and of the blog HumanTransit.org. Passionately interested in an impractical number of fields, he has peerreviewed articles in both the Journal of Transport Geography and Shakespeare Quarterly.

\footnotetext{
${ }^{2}$ The exception is reliability, caused by congestion or incidents, though congestion is predictable to a degree by analyzing it as a pricing failure. Of course the refusal to price road space and most incidents are human factors. Still, we can isolate these human factors and can show that a large part of the analysis of freedom does not rely on them.
} 